\title{
On the Allocative Efficiency of Competitive Prices in Economies with Incomplete Markets
}

\author{
By \\ Tarun Sabarwal ${ }^{1}$ \\ Department of Economics, BRB 1.116 \\ The University of Texas at Austin \\ 1 University Station C3100 \\ Austin TX 78712-0301 USA \\ sabarwal@eco.utexas.edu
}

First Draft: December 2002

This Version: September 30, 2003

\begin{abstract}
A new measure of constrained efficiency for application in economies with incomplete markets is presented. This measure - termed Allais-Malinvaud efficiency - can be viewed as adjusting for market incompleteness not fully captured in previous work. It is shown that equilibrium allocations in Radner-GEI economies are always Allais-Malinvaud efficient. In particular, a re-distribution of assets in equilibrium cannot induce a relative price change that leads to an Allais-Malinvaud improvement. Moreover, this result extends to Radner-GEI economies in which consumer liability is limited by bankruptcy.
\end{abstract}

JEL Numbers: D52, D61

Keywords: Allocative Efficieny, Incomplete Markets, Allais-Malinvaud Efficiency

\footnotetext{
${ }^{1}$ I thank Bob Anderson and Max Stinchcombe for helpful conversations.
} 


\section{Introduction}

The Pareto efficiency of competitive equilibria in Arrow-Debreu economies is one of the strongest welfare results in economics about the allocative efficiency of a competitive price system, but this result depends on the existence of a complete system of competitive markets, in the sense that all commodities in an economy can be simultaneously traded in this system of markets. With complete markets, a competitive price system can indicate scarcity of commodities via relative value, it helps equate marginal rates of substitution across consumers, and it results in a Pareto efficient allocation of commodities.

If the system of markets is incomplete, (in other words, if markets for some commodities do not exist,) then it is well-known that the resulting equilibrium can easily fail to be Pareto efficient. ${ }^{2}$ Moreover, if a system of markets is incomplete at present, (in the sense that some commodities are unavailable for trade at present,) and markets open for trade in the future, (so that these commodities become available for trade in the future,) it is again well-known (as shown by Hart (1975)) that a competitive equilibrium can easily fail to be Pareto efficient.

When markets are incomplete, Pareto efficiency as a measure of allocative efficiency of a price system is a criterion that a price system cannot be reasonably expected to satisfy, because prices cannot allocate commodities that are unavailable for trade. A more relevant measure would evaluate efficiency relative to market incompleteness. What might be such a measure of constrained efficiency, and using such a measure, do competitive prices allocate commodities efficiently when markets are incomplete?

\footnotetext{
${ }^{2}$ For example, if consumption of a particular commodity has an externality, and there is no market for this commodity; or for example, if there are gains from trading a particular commodity, perhaps because of differing marginal rates of substitution, and there is no market for this commodity.
} 
Previous work has postulated different measures of constrained efficiency, as can be seen in Diamond (1967), Grossman (1977), Stiglitz (1982), Newbery and Stiglitz (1982), and Geanakoplos and Polemarchakis (1986). The most general definition and results for exchange economies are presented in Geanakoplos and Polemarchakis (1986), where it is shown that generically, it is possible to re-distribute assets in an equilibrium so that with the new distribution of assets, and correspondingly determined spot-market-clearing prices, individual optimization (for commodities, with the given re-distribution of assets) leads to a Pareto improvement. Intuitively, as described in their paper, and also in Polemarchakis (1990), a re-allocation of assets not only induces an income transfer across periods and states, it further affects equilibrium spot market prices, and can induce a relative price change that can lead to a Pareto improvement.

This paper presents a new definition of constrained efficiency — termed Allais-Malinvaud efficiency. This measure of efficiency can be viewed as adjusting for a type of market incompleteness not fully captured in earlier work. In economies with incomplete markets and sequential trade, there are two types of incompleteness; asset market incompleteness, (which limits income transfers across periods and states,) and commodity market incompleteness, (which limits the collection of commodities that can be traded in a spot market.) Even though consumers do not derive direct utility from assets, they use assets to transfer income to finance the best bundle of goods they can afford, and therefore, in general, opportunities to transfer income as well as opportunities to trade goods jointly affect allocative efficiency. Intuitively, constrained efficiency in Geanakoplos and Polemarchakis (1986) accounts for allocative adjustments arising from asset market incompleteness, and their indirect effect on commodity allocations, whereas Allais-Malivaud efficiency accounts for their combined ef- 
fect by directly incorporating commodity market incompleteness. In other words, Pareto improvements possible in the existing definition of constrained efficiency arise from price changes across time periods or states of the world, (and across periods and states, commodity markets are incomplete,) and not from price changes within a period or state (where commodity markets for spot delivery are complete). In particular, a re-distribution of assets in equilibrium cannot induce a relative price change that leads to an Allais-Malinvaud improvement.

As shown in more detail in the next section, Allais-Malinvaud efficiency can be motivated by considering first a standard Arrow-Debreu economy in which some commodities cannot be traded, in the sense that for a subset of the list of commodities, every commodity in this subset is available for trade for every other commodity in this subset, and no commodity outside this subset can be traded. In this case, a criterion of constrained efficiency would evaluate efficiency relative to the collection of markets available for trade, and would require that no consumer can be made better off without making another consumer worse off in such markets. With this definiton, as documented below, every equilibrium in such an economy is constrained efficient in a fairly obvious manner. Consider next an economy with two periods, where in each period, only commodities for delivery in that period are available for trade. (Hart's example is an example of such an economy.) In such an economy, prices for commodities in one period do not reflect relative value of commodities in the other period, and in this sense, prices in one period cannot allocate commodities in the other period. A relevant measure of constrained efficiency would evaluate efficiency of prices in each period, and would require that no consumer can be made better off without making another consumer worse off in each period. More generally, in economies with incomplete markets 
and sequential trade, including trade in asset markets, a relevant measure of constrained efficiency would evaluate efficiency of prices in each collection of markets in which a price system can indicate relative value. Allais-Malinvaud efficiency formalizes this notion, and it is shown that every equilibrium in such an economy is Allais-Malinvaud efficient.

The criterion of Allais-Malinvaud efficiency used in this paper is adapted from definitions of efficiency first utilized in the context of understanding efficiency of capital accumulation in infinite horizon models in Malinvaud (1953), and in Malinvaud (1962), and additionally utilized in understanding the analogy between atemporal and intertemporal resource allocation in Malinvaud (1961). As mentioned in these papers, Malinvaud draws in part on Allais (1943), and Allais (1947). Versions of ideas from these early papers have been profitably introduced by Balasko and Shell (1980) to understand the allocative efficiency of the price mechanism for economies with overlapping generations, in which, as shown in the early work of Samuelson (1958), and also by Shell (1971), equilibria fail to be Pareto efficient. These ideas have additionally been utilized in Aliprantis, Brown, and Burkinshaw (1989), and a general exposition of these ideas is presented in the elegant monograph by Aliprantis, Brown, and Burkinshaw (1990). The ideas in this paper are also based on the two-period, RadnerGEI model analyzed by Grossman (1977), but there is no claim here that equilibria in the Radner-GEI model cannot in some sense be Pareto improved.

In addition to being a natural analog to Pareto efficiency, Allais-Malinvaud efficiency is conceptually appealing, because it is independent of a particular allocative mechanism, and therefore, at least in principle, it can be applied to allocative mechanisms other than competitive prices. (In contrast, existing definitions of constrained efficiency sometimes rely on competitive prices.) Moreover, it is technically appealing, because formal techniques used to 
show Allais-Malinvaud efficiency can be adapted in a simple and natural manner from wellestablished techniques for complete markets. In particular, additional assumptions needed to apply differential techniques are not required. Furthermore, a slightly more careful adaptation of standard techniques shows that competitive prices continue to allocate commodities efficiently in economies with incomplete markets, sequential trade, and in which consumer liability is limited by bankruptcy. ${ }^{3}$

It is noteworthy that the concept of Allais-Malinvaud efficiency is formalized here specifically to test constrained efficiency when markets are incomplete. In particular, it is not proposed as a replacement for Pareto efficiency as a measure of overall efficiency of resource allocation. The definition of Allais-Malinvaud efficiency presented here is not a desirable measure of overall efficiency, because, as can be seen below, (from its application to Hart's example,) a Pareto improving equilibrium might not be an Allais-Malinvaud improvement, and from the view of overall efficiency of resource allocation, a Pareto improvement is surely desirable. Rather, this analysis shows that when markets are incomplete, prices can nevertheless allocate commodities efficiently relative to market incompleteness. In other words, although Pareto improvements are desirable, competitive equilibria in economies with incomplete markets cannot automatically be expected to exhaust such improvements, but Allais-Malinvaud improvements are a form of constrained improvement, and competitive equilibria exhaust such improvements.

The analysis presented here does not imply that a planner cannot identify welfare-

\footnotetext{
${ }^{3}$ There is as yet no widely accepted theory of production in economies with incomplete markets, and therefore, the results presented here are shown in the case of exchange economies, but the arguments presented here are capable of being adapted to economies with production.
} 
improving asset re-distributions and provide a subsidy for their adoption. However, such an approach would require a planner to make a careful evaluation of the costs of identifying such opportunities versus the welfare-benefits of implementing them. This is possible, but costs of such an approach include potentially large information requirements, and the possibility of introducing additional inefficiencies in the smooth functioning of markets. Indeed, as shown in Geanakoplos and Polemarchakis (1990), for a planner to implement a Paretoimproving re-distribution of assets, it is essential for her to observe excess demand for assets and commodities for every consumer as all prices and revenues vary, (and not just for equilibrium prices,) and moreover, when markets clear sequentially, a planner's information is always insufficient to contradict the claim of optimality of equilibrium, and therefore, with sequential market clearing, she cannot determine Pareto-improving re-distributions from available information. Furthermore, even when Pareto-improving re-distributions of assets are available, it is not yet known that a particular such re-distribution can be decentralized, because there is not yet an argument that a re-distributed asset-holding is optimal for a consumer, even if it is affordable. Nevertheless, the analysis here does not automatically imply that there are no situations in which a planner's intervention is useful.

This paper is organized as follows. Section 2 motivates the idea of efficiency relative to market incompleteness, and motivates the idea of Allais-Malinvaud efficiency. Section 3 documents the constrained Pareto efficiency of every equilibrium in an economy in which a subset of commodities cannoted be traded (termed an Arrow-Debreu economy with incomplete markets). Section 4 defines a Radner-GEI economy (an economy with incomplete markets and sequential trade), defines Allais-Malinvaud efficiency, and shows the AllaisMalinvaud efficiency of every equilibrium in a Radner-GEI economy. Section 5 defines a 
Radner-GEI economy in which consumer liability is limited by bankruptcy, and shows the Allais-Malinvaud efficiency of every equilibrium in such an economy.

\section{Efficiency Relative to Market Incompleteness:}

\section{A Motivation}

To motivate the idea of efficiency relative to market incompleteness, consider, as a first step, an economy in which some commodities cannot be traded. This can be formalized in the context of an Arrow-Debreu economy by positing a subset of the list of commodities such that every commodity in this subset is available for trade for every other commodity in this subset, and no commodity outside this subset can be traded. Therefore, for each commodity unavailable for trade, consumers are constrained to consume their endowment of this commodity. In this paper, such an economy is termed an Arrow-Debreu economy with incomplete markets. In such an economy, a natural definition of equilibrium is a collection of prices, one for each commodity available for trade, and a collection of consumption plans, one for each consumer, such that consumers are optimizing, and markets are clearing. In this case, prices cannot allocate commodities that are unavailable for trade, and Pareto efficiency as a measure of allocative efficiency is a criterion that a price system cannot be reasonably expected to satisfy. A more relevant criterion would evaluate efficiency relative to those allocations of consumption plans that a consumer can achieve with markets available for trade, and in this paper, such a criterion is termed constrained Pareto efficiency. With this definiton, every equilibrium in an Arrow-Debreu economy with incomplete markets is 
constrained Pareto efficient in a fairly obvious manner. It appears that such a result is not yet formalized and documented in the literature. This paper documents the constrained Pareto efficiency of competitive equilibria in Arrow-Debreu economies with incomplete markets.

Consider next an economy in which some commodities are not available for trade at present, and these commodities become available for trade in the future. In this case, consumers could benefit from trade both at present and in the future. ${ }^{4}$ The seminal paper by Radner (1972) formalizes sequential trade over time when markets are incomplete in the sense that at a given date, all commodities at that date can be traded, but some commodites for future delivery cannot be traded. ${ }^{5}$ Radner's model and some of its extensions are also referred to as a model of general equilibrium with incomplete markets (or GEI model).

As in an Arrow-Debreu economy with incomplete markets, an equilibrium in an economy with sequential trade over time cannot reasonably be expected to be Pareto efficient. Indeed, in the influential paper by Hart (1975), it is shown that a competitive equilibrium in a twoperiod Radner-GEI economy can be Pareto inefficient, and moreover, it is Pareto inefficient relative to the collection of consumption plans achievable with incomplete markets. More surprisingly, it is also shown that a competitive equilibrium in such an economy can be Pareto dominated by another competitive equilibrium in the same economy.

The idea of Allais-Malinvaud efficiency can be motivated by noticing first that the concept

\footnotetext{
${ }^{4}$ It is noteworthy that for trade to occur when markets open in the future, it is necessary that markets at present be incomplete, because if markets at present are complete, then it is well-known that there is no gain from opening markets in the future.

${ }^{5}$ As any reasonable interpretation of a realistic economy would conclude that in any period, markets for commodites available for trade in that period are incomplete, Radner's model would be a natural model in which to study the allocation of resources in economies when markets are incomplete.
} 
of an Arrow-Debreu economy with incomplete markets mentioned above separates the idea of incomplete markets (some commodities cannot be traded) from the idea of sequential trade (there is trade over time), and this separation sheds more light on Hart's example. In a Radner-GEI economy, these ideas are combined - in the sense that some commodities cannot be traded in one time period, but there is trade over time, and these commodities can be traded in another time period.

Hart's example is an example of a two-period Radner-GEI economy with two consumers, and two commodities in each period. In this economy, in period 1, markets for trade in commodities for delivery in period 2 do not exist, but these become available for trade in period 2 . As shown in Figure 1, this economy has four possible equilibria: $(A, C),(B, C),(A, D),(B, D)$ with corresponding combinations of prices $p_{1}, p_{2}, \pi_{1}, \pi_{2}$. With additively separable intertemporal utilities for consumers, if Consumer 1 prefers relatively strongly to consume in period 1, and Consumer 2 in period 2, then allocation $(B, C)$ Pareto dominates $(A, D)$ even though both allocations can be realized as equilibrium allocations. Hart's example can be thought of as positing two disjoint subsets of commodities, and requiring commodities in each subset to be traded for commodities in that subset alone, and not for commodities in the other subset. ${ }^{6}$ Prices for commodities in one subset cannot allocate commodities in the other subset, because they cannot reflect relative value of those commodities, so a more relevant measure of allocative efficiency of a price system would evaluate efficiency of prices in each collection of markets in which a price system can indicate relative value. Indeed, as Figure 1 intuitively shows, prices are efficient in each period in which they can

\footnotetext{
${ }^{6}$ The author is grateful to Bob Anderson for mentioning this logical equivalence as a relation of Hart's example to an Arrow-Debreu economy with incomplete markets.
} 
allocate commodities, in the sense that in each period, no consumer can be made better off without making another consumer worse off. Essentially, relative to market incompleteness, prices are allocating commodities in spot markets where their mechanism of relative value is (relatively) complete, and therefore, (relatively) efficient. The Pareto inefficiency in Hart's example is emerging from the exogenous incompleteness imposed on the trading structure.

\section{[Insert Figure 1 here]}

More generally, the mechanism of competitive prices in a Radner-GEI economy cannot be reasonably expected to satisfy Pareto efficiency, because if markets for some commodities do not exist at present, then the price system at present is not an indicator of the relative value of these commodities, and therefore, it cannot indicate their scarcity. That job is done naturally by the price system in the future when these commodities are available for trade. A more relevant measure would evaluate efficiency of a price system whenever a price system can indicate scarcity via relative value. More formally, the modeling of sequential trade over time imposes a different price system at every node of a Radner-GEI economy, the price system at each node can only indicate relative value of commodities and assets at that node, and therefore, a more relevant measure of efficiency would evaluate efficiency of an equilibrium allocation at each node. Allais-Malinvaud efficiency formalizes this idea. ${ }^{7}$ It is shown that every equilibrium in a Radner-GEI economy is Allais-Malinvaud efficient. In particular, this implies that a re-distribution of assets accompanied with spot-market-clearing prices cannot induce an Allais-Malinvaud improvement. Consumers are using asset markets (relatively)

\footnotetext{
${ }^{7}$ Notice that another conceptually appealing feature of Allais-Malinvaud efficiency is that it applies to Hart's example in an intuitive manner.
} 
efficiently, in the sense that at each node, individual marginal rates of substitution coincide with relative prices, and further budget-balancing, asset-market transfers cannot induce, at any node, improvements for some consumer without making another consumer worse off.

As mentioned above, the formal techniques used to show Allais-Malinvaud efficiency can be adapted in a relatively straightforward and natural manner from well-established techniques for complete markets. In particular, adapting a well-established proof of Pareto efficiency with complete markets, it is shown that an allocation in a Radner equilibrium is Allais-Malinvaud efficient. Moreover, Allais-Malinvaud efficiency is applicable in economies with incomplete markets, trade over time, and consumer liability limited by bankruptcy, as formalized by an extension of the Radner-GEI model presented in Sabarwal (2003). A more careful adaptation of a standard proof shows that an allocation in a bankruptcy equilibrium is Allais-Malinvaud efficient.

\section{Incomplete Markets}

Markets for commodities might not exist for several well-known reasons, including externalities, asymmetric information, legal restrictions, technologial limitations, set-up costs, and the extensive number of markets required by the definition of an economic commodity. Examples include the absence of a functioning market for neighborhood sound pollution, for library or public park services, for the one-day service use of a ten-year old car, for the one-month service use of a five-year old television, for wine shipment across some political units, for gambling in several political units, for trading exemptions under bankruptcy law (these are unenforceable contracts), for oil drilling in protected areas, for DNA repair, for 
molecularly assembled machines, for curing AIDS, for space travel, or for nuclear power plants. Moreover, a good or service with a different date or location of delivery is a different economic commodity, and therefore, a complete set of markets requires a market for each combination of each conceivable elementary physical attribute of a good or service, each elementary location, and each elementary time interval. This requirement is obviously very restrictive, and certainly not fulfilled; for example, there is no functioning market for smoking rights in a public place in Bethesda, Maryland, for delivery of ivory tusks of African elephants in any location in the United States, for delivery of Hollywood movies in some locations in the world, for mail delivery at night, for the services of a chinese food restaurant in Berkeley, California at 2 am, and so on.

Consider an economy in which markets for some commodities do not exist. This can be formalized in the context of an Arrow-Debreu economy by positing a subset of the list of commodities such that every commodity in this subset is available for trade for every other commodity in this subset, and no commodity outside this subset can be traded. Therefore, for each commodity unavailable for trade, consumers are constrained to consume their endowment of this commodity. For each commodity available for trade there is a price, and at these prices, consumers can afford some bundles of tradable commodities. Consumers then choose the best consumption plan that they can afford. An equilibrium consists of prices for commodities available for trade, and optimal consumer choices at these prices, such that total demand equals total supply. Such an economy is termed an Arrow-Debreu economy with incomplete markets, and it is formalized below.

In an Arrow-Debreu economy with incomplete markets, prices cannot allocate commodities for which there are no markets, and Pareto efficiency as a measure of allocative efficiency 
is a criterion that a price system cannot be reasonably expected to satisfy. A more relevant measure would be one that is restricted to markets in which a price system applies, and in these markets, such a measure would require that no consumer can be made better off without making another consumer worse off. Such a measure is termed constrained Pareto efficiency, and it is defined below. It is shown that every equilibrium in an Arrow-Debreu economy with incomplete markets is constrained Pareto efficient.

An Arrow-Debreu economy with incomplete markets can be formalized as follows. There are a finite number of commodities, indexed $\ell=1, \ldots, L$, and a fixed subset of these, say the first $\hat{L}$ commodities (with $\hat{L} \leq L$ ), are available for trade. The consumption space is $X=\left(\Re^{L}\right)_{+}$, and the trade space is $\hat{X}=\left(\Re^{\hat{L}}\right)_{+}$. A consumption plan is an element $x \in X$, and it entails consumption of $x_{\ell}$ units of good $\ell$. A tradable plan is an element $\hat{x} \in \hat{X}$. The restriction of a consumption plan $x$ to the trade space is a tradable plan $\hat{x} \in \hat{X}$, with $\hat{x}_{\ell}=x_{\ell}$ for each $\ell=1, \ldots, \hat{L}$. Each commodity available for trade has a price. The price space is $\Delta=\left\{p \in \Re_{+}^{\hat{L}} \mid \sum_{\ell} p_{\ell}=1\right\}$. A price system is an element $p \in \Delta$ with $p_{\ell}$ the price of a unit of commodity $\ell$.

There are a finite number of consumers, or individuals, indexed $i=1, \ldots, I$. Each consumer $i$ has a preference relation, $\succeq^{i} \subset X \times X$. A preference relation is complete, reflexive, transitive, convex, continuous, and strongly monotone $\left(x>\dot{x} \Rightarrow x \succ^{i} \dot{x}\right){ }^{8}$ Each consumer $i$ has an endowment of consumption goods, $w^{i} \in X$. The collection of endowments,

\footnotetext{
${ }^{8}$ The notions of indifference $\left(\sim^{i}\right)$ and strict preference $\left(\succ^{i}\right)$ are the usual ones. Moreover, partial order on $\Re^{K}, K=1,2, \ldots$, is the usual one: $x \geq y$ means $x_{k} \geq y_{k}, k=1, \ldots, K ; x>y$ means $x \geq y$ and $x \neq y$; $x \gg y$ means $x_{k}>y_{k}, k=1, \ldots, K$. For $E \subset \Re^{K}, E_{+}$is the set of those elements in $E$ which are greater than or equal to 0 .
} 
$\left(w^{i}\right)_{i=1}^{I}$ satisfies $\inf _{i} w^{i} \gg 0$. For each consumer $i$, the extension of a tradable plan $\hat{x} \in \hat{X}$ is the consumption plan $x \in X$ with $x_{\ell}=\hat{x}_{\ell}$ for $\ell \leq \hat{L}$, and $x_{\ell}=w_{\ell}^{i}$ otherwise. The consumption space for consumer $i$ is the collection of extensions of tradable plans, and it is denoted $X^{i} \subset X$. A consumption plan for consumer $i$ is an element of $X^{i}$.

For a price system $p$, the value of a consumption plan $x \in X^{i}$ for consumer $i$ is $p \hat{x}$, the income of consumer $i$ is $p \hat{w}^{i}$, and a consumption plan for consumer $i$ is affordable at price $p$, if its value is less than or equal to consumer $i$ 's income. A demand by consumer $i$ at price $p$ is a maximal element of the consumer's preference relation in the set of all consumption plans for consumer $i$ that are affordable at price $p$.

An Arrow-Debreu economy with incomplete markets is a collection

$$
\mathcal{E}=\left\{L, \hat{L},\left(\succeq^{i}, w^{i}\right)_{i=1}^{I}\right\}
$$

where $L$ is the number of commodities, and $\hat{L} \leq L$ of these are available for trade, and $\left(\succeq^{i}, w^{i}\right)$ is the preference relation and endowment of consumer $i$. An Arrow-Debreu equilibrium with incomplete markets is a collection $\left(p,\left(x^{i}\right)_{i=1}^{I}\right)$, where $p$ is a price system, $\left(x^{i}\right)_{i=1}^{I}$ is a collection of consumption plans, with $x^{i}$ a demand for consumer $i$ at price $p$, and $\sum_{i=1}^{I} x^{i}=\sum_{i=1}^{I} w^{i}$. In other words, an Arrow-Debreu equilibrium with incomplete markets is a collection of prices, one for each commodity available for trade, and consumption plans, one for each consumer, such that consumers are optimizing, and markets are clearing.

The notion of constrained Pareto efficiency is defined as follows. An allocation is a collection of consumption plans, one for each consumer, say $x=\left(x^{i}\right)_{i=1}^{I}$, where $x^{i} \in X^{i}$, and $\sum_{i=1}^{I} x^{i}=\sum_{i=1}^{I} w^{i}$. An allocation $x$ constrained Pareto dominates an allocation $x$, if for every $i, x^{i} \succeq^{i} x^{i}$, and for some $i, x^{i} \succ^{i} x^{i}$. An allocation $x$ is constrained Pareto 
efficient, if there is no allocation $x$ that constrained Pareto dominates $x$. The theorem below shows that in economies with incomplete markets, a competitive price system allocates commodities efficiently in markets in which it applies.

Theorem 0. Every Arrow-Debreu equilibrium with incomplete markets is constrained Pareto efficient.

Proof. Let $\left(p,\left(x^{i}\right)_{i=1}^{I}\right)$ be an Arrow-Debreu equilibrium with incomplete markets. From the definition of equilibrium, we know that $\left(x^{i}\right)_{i=1}^{I}$ is an allocation. Suppose there is another allocation, denoted $\left(y^{i}\right)_{i=1}^{I}$, that constrained Pareto dominates this allocation; that is, for every $i, y^{i} \succeq^{i} x^{i}$, and for some $i, y^{i} \succ^{i} x^{i}$. From the maximality of $x^{i}$, and the monotonicity of $\succeq^{i}$, we know that for every $i, p \hat{y}^{i} \geq p \hat{w}^{i}$, and for some $i, p \hat{y}^{i}>p \hat{w}^{i}$. From the definition of an allocation, it follows that $\sum_{i=1}^{I} \hat{y}^{i}=\sum_{i=1}^{I} \hat{w}^{i}$. Therefore,

$$
\sum_{i=1}^{I} p \hat{w}^{i}=\sum_{i=1}^{I} p \hat{y}^{i}>\sum_{i=1}^{I} p \hat{w}^{i}
$$

a contradiction.

\section{Incomplete Markets and Sequential Trade}

If some commodities are not available for trade at present, and these commodities become available for trade in the future, then consumers could benefit from trade both at present and in the future. The seminal paper by Radner (1972) formalizes a model of an economy with incomplete markets and sequential trade. In each period and state, consumers can trade only in commodities and assets for which markets exist in that period and state. There are consumption goods and assets, and consumers use assets to move income among different 
time periods, and among different states of the world to finance a consumption plan that they desire most. An equilibrium is a collection of prices, one set of relative prices for each period and state, and a collection of demands, one for each consumer, such that, at this collection of prices, total demand by consumers equals total supply. ${ }^{9}$ Radner's model and some of its extensions are also referred to as a model of general equilibrium with incomplete markets (GEI model). Such a model is formalized below.

As in an Arrow-Debreu economy with incomplete markets, the mechanism of competitive prices in a Radner-GEI economy cannot be reasonably expected to satisfy Pareto efficiency. As described above, a more relevant measure of allocative efficiency would evaluate the efficiency of an equilibrium allocation in each period and state of the world, (equivalently, at each node,) and it would require that in each period and state of the world, no consumer can be made better off without making another consumer worse off. Such a measure is termed Allais-Malinvaud efficiency, and it is defined below. It is shown that every Radner equilibrium is Allais-Malinvaud efficient.

A Radner-GEI economy is formalized as follows. Trade takes place over time, and there is uncertainty. Economic activity takes place over a finite number of elementary time periods, indexed $t=1, \ldots, T$, and a finite number of states of the world, indexed $s=1, \ldots, S$. Each state $s$ is a particular history of the environment from period 1 through period $T$. The events observable in period $t$ are given by a partition $\mathcal{S}_{t}$ of $\{1, \ldots, S\}$. To reflect dependence of actions in period $t$ on events observable in that period, a function on $\{1, \ldots, S\}$ is said to be $\mathcal{S}_{t}$-measurable if it is constant on each event $E_{t} \in \mathcal{S}_{t}$. To reflect the additional availability of information as time goes on, the sequence of partitions, $\mathcal{S}=\left(\mathcal{S}_{t}\right)_{t=1}^{T}$, is taken to be

\footnotetext{
${ }^{9}$ In equilibrium, assets are in zero net supply.
} 
nondecreasing in fineness, and it is termed an information structure. For $t=1, \ldots, T$, let $\mathcal{R}_{t}=\left\{\left(\xi_{t}(s)\right)_{s=1}^{S} \in \Re^{S} \mid \xi_{t}(\cdot)\right.$ is $\mathcal{S}_{t}$-measurable $\}$ be the subspace of $\Re^{S}$ consisting of vectors which are $\mathcal{S}_{t}$-measurable and let $\mathcal{R}=\underset{t=1}{\underset{T}{\times}} \mathcal{R}_{t}$.

In each period $t$, state $s$, there are a finite number of commodities, indexed $\ell=1, \ldots, L$. The consumption space in period $t$ is $X_{t}=\left(\mathcal{R}_{t}^{L}\right)_{+}$, and the consumption space is $X=\underset{t=1}{\mathrm{~T}} X_{t}$. A consumption plan is an element $x=\left(x_{t}\right)_{t=1}^{T} \in X$, and it entails consumption of $x_{t}(s)_{\ell}$ units of good $\ell$ in the period $t$, state $s$.

There are a finite number of assets, indexed $j=1, \ldots, J .{ }^{10}$ Their payoff in the period $t$, state $s$ is summarized by a $L \times J$ matrix of asset returns, denoted $A_{t}(s)$. Its $l j$-th component, denoted $A_{t}(s)_{\ell, j}$, specifies the (non-negative) payoff of asset $j$ in period $t$, state $s$ in terms of good $\ell$. For convenience, $A_{1}$ is taken to be the zero matrix, and to reflect the dependence of asset returns on the information available, for each $t \geq 2, A_{t}(\cdot)$ is taken to be $\mathcal{S}_{t}$-measurable. An asset structure is a sequence of asset return matrices, $A=\left(A_{t}\right)_{t=1}^{T}$. Portfolios of assets are defined as follows. The portfolio space in period $t \leq T-1$ is $Z_{t}=\mathcal{R}_{t}^{J}$, and that in period $t=T$ is $Z_{T}=\{0\} \subset \mathcal{R}_{T}^{J}$. The portfolio space is $Z=\underset{t=1}{\underset{T}{\times}} Z_{t}$. A portfolio plan is an element $z=\left(z_{t}\right)_{t=1}^{T} \in Z$, and it entails holding $z_{t}(s)_{j}$ units of asset $j$ in period $t$, state $s$. Occasionally, the notation $z_{t-1}$, where $t=1$, shall be encountered; in such a case, $z_{0}$ is defined to be 0 .

Prices of commodities and assets are defined as follows. The price space in period $t \leq$ $T-1$ is $\Delta_{t}=\left\{\left(p_{t}, q_{t}\right) \in\left(\mathcal{R}_{t}^{L+J}\right)_{+} \mid\right.$for every $\left.s, \sum_{\ell} p_{t}(s)_{\ell}+\sum_{j} q_{t}(s)_{j}=1\right\}$, and that in period $t=T$ is $\Delta_{T}=\left\{\left(p_{T}, 0\right) \in\left(\mathcal{R}_{T}^{L+J}\right)_{+} \mid\right.$for every $\left.s, \sum_{\ell} p_{T}(s)_{\ell}=1\right\}$. The price space is

\footnotetext{
${ }^{10}$ In this model, assets have long lives. However, it is easy to incorporate in this model assets with short lives. The results in this section and the next section remain true if assets have short lives.
} 
$\Delta=\underset{t=1}{\stackrel{T}{\times}} \Delta_{t}$. A price system is an element $(p, q) \in \Delta$, with $p_{t}(s)_{\ell}$ the price of a unit of good $\ell$ in period $t$, state $s$, and $q_{t}(s)_{j}$ the price of a unit of asset $j$ in period $t$, state $s$.

There are a finite number of consumers, indexed $i=1, \ldots, I$. Each consumer $i$ has a preference relation, $\succeq^{i} \subset X \times X$, and this relation is complete, reflexive, transitive, convex, continuous, and strongly monotone $\left(x>\dot{x} \Rightarrow x \succ^{i} \dot{x},\right)^{11}$ and an endowment, $w^{i}=\left(w_{t}^{i}\right)_{t=1}^{T} \in$ $X$. The collection of endowments satisfies $\inf _{i} w^{i} \gg 0$. When convenient, $x_{t}^{i}(s)$ denotes a consumption plan for consumer $i$ in period $t$, state $s$, and $\left(x_{t}^{i}(s)\right)_{i=1}^{I}$ denotes a consumption profile in period $t$, state $s$.

For a price system $(p, q)$, and a consumption and portfolio plan $\left(x^{i}, z^{i}\right)$ for consumer $i$, the disposable income of consumer $i$ in period $t$, state $s$ is

$$
W^{i}\left(p, q, z^{i}\right)_{t}(s)=p_{t}(s) w_{t}^{i}(s)+\left[p_{t}(s) A_{t}(s)+q_{t}(s)\right] z_{t-1}^{i}(s)
$$

and $\left(x^{i}, z^{i}\right)$ is $(p, q)$-affordable if in every period $t$, state $s, p_{t}(s) x_{t}^{i}(s)+q_{t}(s) z_{t}^{i}(s) \leq$ $W^{i}\left(p, q, z^{i}\right)_{t}(s){ }^{12}$ A consumer's budget set consists of all consumption and portfolio plans that are affordable, and her demand set consists of those plans in the budget set which are optimal with respect to her preference relation. For a price system $(p, q)$, the budget set for consumer $i$ is

$$
B^{i}(p, q)=\left\{\left(x^{i}, z^{i}\right) \in X \times Z \mid\left(x^{i}, z^{i}\right) \text { is }(p, q) \text {-affordable }\right\}
$$

and the demand set for consumer $i$ is

$$
D^{i}(p, q)=\left\{\left(x^{i}, z^{i}\right) \in B^{i}(p, q) \mid\left(\dot{x}^{i}, \dot{z}^{i}\right) \in B^{i}(p, q) \Rightarrow x^{i} \succeq^{i} \dot{x}^{i}\right\}
$$

\footnotetext{
${ }^{11}$ The notions of indifference $\left(\sim^{i}\right)$ and strict preference $\left(\succ^{i}\right)$ are the usual ones.

${ }^{12}$ Notably, in period $t=1$, state $s, W^{i}\left(p, q, z^{i}\right)_{t}(s)=p_{1}(s) w_{1}^{i}(s)$.
} 


\section{A Radner-GEI economy is a collection}

$$
\left\{\mathcal{S}, A,\left(\succeq^{i}, w^{i}\right)_{i=1}^{I},\right\}
$$

where $\mathcal{S}=\left(\mathcal{S}_{t}\right)_{t=1}^{T}$ is an information structure, $A=\left(A_{t}\right)_{t=1}^{T}$ is an asset structure, $\left(\succeq^{i}, w^{i}\right)$ is the preference relation and endowment of consumer $i .^{13}$ A Radner equilibrium is a collection $\left(p, q ;\left(x^{i}, z^{i}\right)_{i=1}^{I}\right)$, where $(p, q)$ is a price system, and for every $i,\left(x^{i}, z^{i}\right) \in D^{i}(p, q)$, and in every period $t$, state $s, \quad \sum_{i=1}^{I} x_{t}^{i}(s)=\sum_{i=1}^{I} w_{t}^{i}(s)$ and $\sum_{i=1}^{I} z_{t}^{i}(s)=0$. In other words, a Radner equilibrium is a collection of prices, one set for each period and state when markets for trade are open, and individual consumption and portfolio plans, one for each consumer, such that consumers are optimizing, and in every period and state, markets are clearing. ${ }^{14}$

The idea of making a consumer better off in a given period and state can be motivated by considering a consumer $i$ with preference relation $\succeq^{i}$, and a consumption plan $x^{i}$, and naturally deriving a preference for consumption in a given period and state as follows. In a particular period $t$, state $s$, consumer $i$ prefers a bundle of commodities $\dot{x}_{t}^{i}(s)$ to $x_{t}^{i}(s)$, if she prefers the consumption plan that is derived from $x^{i}$ by replacing $x_{t}^{i}(s)$ with $\dot{x}_{t}^{i}(s)$ to the consumption plan $x^{i}$. More formally, let $x^{i}$ be a consumption plan for consumer $i$, and let $\succeq^{i}$ be the preference of consumer $i$. If $\dot{x}_{\hat{t}}^{i}(\hat{s})$ is a consumption plan for consumer $i$ in

\footnotetext{
${ }^{13}$ Hart's example is an example of a Radner-GEI economy with two periods $(T=2)$, no uncertainty ( $S=1)$, two goods in each period $(L=2)$, and no assets $(J=0$, or equivalenty, degenerate assets, as in $\left.A_{2}=0\right)$.
}

${ }^{14}$ The question of existence of equilibrium with bounds on short sales of assets is considered in Radner (1972), and without bounds on short sales is considered in Duffie and Shafer (1985) and Duffie and Shafer (1986). 
period $\hat{t}$, state $\hat{s}$, then consumer $i$ prefers $x_{\hat{t}}^{i}(\hat{s})$ to $x_{\hat{t}}^{i}(\hat{s})$ in period $\hat{t}$, state $\hat{s}$, denoted $x_{\hat{t}}^{i}(\hat{s}) \succeq_{\hat{t}}^{i}(\hat{s}) x_{\hat{t}}^{i}(\hat{s})$, if $\hat{x}^{i} \succeq^{i} x^{i}$, where $\hat{x}^{i}$ is defined as follows: $\hat{x}_{t}^{i}(s)=\dot{x}_{t}^{i}(s)$ if $t=\hat{t}$ and $s=$ $\hat{s}$, and $\hat{x}_{t}^{i}(s)=x_{t}^{i}(s)$ otherwise. Consumer $i$ strictly prefers $x_{\hat{t}}^{i}(\hat{s})$ to $x_{\hat{t}}^{i}(\hat{s})$ in period $\hat{t}$, state $\hat{s}$, denoted $\dot{x}_{\hat{t}}^{i}(\hat{s}) \succ_{\hat{t}}^{i}(\hat{s}) x_{\hat{t}}^{i}(\hat{s})$, if $\hat{x}^{i} \succ^{i} x^{i}$.

Let $\succeq^{i}$ be the preference of consumer $i$, and let $x^{i}$ be a consumption plan for consumer $i$. The preference $\succeq_{t}^{i}(s)$ is weakly monotone in period $t$, state $s$, if for every consumption plan $x_{t}^{i}(s)$ in period $t$, state $s, x_{t}^{i}(s) \gg x_{t}^{i}(s) \Rightarrow x_{t}^{i}(s) \succ_{t}^{i}(s) x_{t}^{i}(s)$. Notice that if $\succeq^{i}$ is strongly monotone, then $\succeq_{t}^{i}(s)$ is weakly monotone in period $t$, state $s$, for every period $t$, state $s$. Moreover, if $\succeq_{t}^{i}(s)$ is weakly monotone in period $t$, state $s$, for every period $t$, state $s$, then $\succeq^{i}$ is weakly monotone.

A profile of consumption plans in period $t$, state $s,\left(x_{t}^{i}(s)\right)_{i=1}^{I}$, is an allocation in period $t$, state $s$, if $\sum_{i=1}^{I} x_{t}^{i}(s)=\sum_{i=1}^{I} w_{t}^{i}(s)$. A profile of consumption plans, $\left(x^{i}\right)_{i=1}^{I}$, is an allocation, if for every period $t$, state $s,\left(x_{t}^{i}(s)\right)_{i=1}^{I}$ is an allocation in period $t$, state $s$. Let $x=\left(x^{i}\right)_{i=1}^{I}$ be an allocation. A period $\hat{t}$, state $\hat{s}$ allocation $\left(\hat{x}_{\hat{t}}^{i}(\hat{s})\right)_{i=1}^{I}$ Allais-Malinvaud dominates allocation $\left(x^{i}\right)_{i=1}^{I}$ in period $\hat{t}$, state $\hat{s}$, if for every consumer $i, x_{\hat{t}}^{i}(\hat{s}) \succeq_{\hat{t}}^{i}(\hat{s}) x_{\hat{t}}^{i}(\hat{s})$, and for some consumer $i, x_{\hat{t}}^{i}(\hat{s}) \quad \succ_{\hat{t}}^{i}(\hat{s}) \quad x_{\hat{t}}^{i}(\hat{s})$. An allocation $\left(\hat{x}^{i}\right)_{i=1}^{I}$ Allais-Malinvaud dominates allocation $\left(x^{i}\right)_{i=1}^{I}$, if there is some period $\hat{t}$, state $\hat{s}$, such that $\left(\hat{x}_{\hat{t}}^{i}(\hat{s})\right)_{i=1}^{I}$ Allais-Malinvaud dominates $\left(x^{i}\right)_{i=1}^{I}$ in period $\hat{t}$, state $\hat{s}$. An allocation $\left(x^{i}\right)_{i=1}^{I}$ is Allais-Malinvaud efficient, if there is no allocation $\left(\dot{x}^{i}\right)_{i=1}^{I}$ that Allais-Malinvaud dominates $\left(x^{i}\right)_{i=1}^{I}$. A Radner equilibrium $\left(p, q ;\left(x^{i}, z^{i}\right)_{i=1}^{I}\right)$ is Allais-Malinvaud efficient if $\left(x^{i}\right)_{i=1}^{I}$ is Allais-Malinvaud efficient. ${ }^{15}$ With

\footnotetext{
${ }^{15}$ Intuitively, a Radner equilibrium is constrained inefficient if there is even one node where goods can be re-distributed, whether using asset-redistributions or some other means, to make someone better off at this node without making anyone worse off.
} 
these definitions, every Radner equilibrium is Allais-Malinvaud efficient, as the following theorem shows.

Lemma 1. Let $(p, q)$ be a price system, $\left(x^{i}, z^{i}\right) \in D^{i}(p, q)$, and $x^{i}$ be another consumption plan for $i$. In period $\hat{t}$, state $\hat{s}$,

$$
\begin{aligned}
& \text { if } \quad \dot{x}_{\hat{t}}^{i}(\hat{s}) \succeq_{\hat{t}}^{i}(\hat{s}) x_{\hat{t}}^{i}(\hat{s}), \text { then } p_{\hat{t}}(\hat{s}) \dot{x}_{\hat{t}}^{i}(\hat{s})+q_{\hat{t}}(\hat{s}) z_{\hat{t}}^{i}(\hat{s}) \geq W^{i}\left(p, q, z^{i}\right)_{\hat{t}}(\hat{s}), \quad \text { and } \\
& \text { if } \quad \dot{x}_{\hat{t}}^{i}(\hat{s}) \succ_{\hat{t}}^{i}(\hat{s}) x_{\hat{t}}^{i}(\hat{s}), \text { then } p_{\hat{t}}(\hat{s}) \dot{x}_{\hat{t}}^{i}(\hat{s})+q_{\hat{t}}(\hat{s}) z_{\hat{t}}^{i}(\hat{s})>W^{i}\left(p, q, z^{i}\right)_{\hat{t}}(\hat{s}) .
\end{aligned}
$$

Proof. To prove the first statement, suppose its hypothesis is true, and suppose that $p_{\hat{t}}(\hat{s}) \dot{x}_{\hat{t}}^{i}(\hat{s})+q_{\hat{t}}(\hat{s}) z_{\hat{t}}^{i}(\hat{s})<W^{i}\left(p, q, z^{i}\right)_{\hat{t}}(\hat{s})$. Then there is $\hat{x}_{\hat{t}}^{i}(\hat{s}) \gg \dot{x}_{\hat{t}}^{i}(\hat{s})$ such that $p_{\hat{t}}(\hat{s}) \hat{x}_{\hat{t}}^{i}(\hat{s})+$ $q_{\hat{t}}(\hat{s}) z_{\hat{t}}^{i}(\hat{s}) \leq W^{i}\left(p, q, z^{i}\right) \hat{\hat{t}}(\hat{s})$, and therefore, if the consumption plan $\hat{x}^{i}$ is defined as $\hat{x}_{t}^{i}(s)=$ $\hat{x}_{\hat{t}}^{i}(\hat{s})$ if $t=\hat{t}$ and $s=\hat{s}$, and $\hat{x}_{t}^{i}(s)=x_{t}^{i}(s)$ otherwise, then $\left(\hat{x}^{i}, z^{i}\right) \in B^{i}(p, q)$. Moreover, if the consumption plan $\tilde{x}^{i}$ is defined as $\tilde{x}_{t}^{i}(s)=\hat{x}_{t}^{i}(s)$ if $t=\hat{t}$ and $s=\hat{s}$, and $\tilde{x}_{t}^{i}(s)=$ $x_{t}^{i}(s)$ otherwise, then $\hat{x}_{\hat{t}}^{i}(\hat{s}) \gg \hat{x}_{\hat{t}}^{i}(\hat{s})$ implies $\hat{x}^{i} \succ^{i} \tilde{x}^{i}$, and $\hat{x}_{\hat{t}}^{i}(\hat{s}) \succeq_{t}^{i}(s) x_{\hat{t}}^{i}(\hat{s})$ implies $\tilde{x}^{i} \succeq^{i} x^{i}$. In particular, $\hat{x}^{i} \succ^{i} x^{i}$, contradicting the optimality of $x^{i}$.

To prove the second statement, suppose its hypothesis is true, and suppose that $p_{\hat{t}}(\hat{s}) \hat{x}_{\hat{t}}^{i}(\hat{s})+$ $q_{\hat{t}}(\hat{s}) z_{\hat{t}}^{i}(\hat{s}) \leq W^{i}\left(p, q, z^{i}\right)_{\hat{t}}(\hat{s})$. In this case, if the consumption plan $\tilde{x}^{i}$ is defined as $\tilde{x}_{t}^{i}(s)=\dot{x}_{t}^{i}(s)$ if $t=\hat{t}$ and $s=\hat{s}$, and $\tilde{x}_{t}^{i}(s)=x_{t}^{i}(s)$ otherwise, then $\left(\tilde{x}^{i}, z^{i}\right) \in B^{i}(p, q)$. Moreover, $\hat{x}_{\hat{t}}^{i}(\hat{s}) \succ_{\hat{t}}^{i}(\hat{s}) x_{\hat{t}}^{i}(\hat{s})$ implies $\tilde{x} \succ^{i} x^{i}$, contradicting the optimality of $x^{i}$.

Theorem 1. Every Radner equilibrium is Allais-Malinvaud efficient.

Proof. Suppose $\left(p, q ;\left(x^{i}, z^{i}\right)_{i=1}^{I}\right)$ is a Radner equilibrium, and suppose there is an allocation $\left(\dot{x}^{i}\right)_{i=1}^{I}$ that Allais-Malinvaud dominates $\left(x^{i}\right)_{i=1}^{I}$. Therefore, there is period $\hat{t}$, state $\hat{s}$ such that for every consumer $i, \dot{x}_{\hat{t}}^{i}(\hat{s}) \succeq_{\hat{t}}^{i}(\hat{s}) x_{\hat{t}}(\hat{s})$, and for some consumer $i, \dot{x}_{\hat{t}}^{i}(\hat{s}) \succ_{\hat{t}}^{i}(\hat{s}) x_{\hat{t}}(\hat{s})$. From the definition of equilibrium, $\left(x^{i}, z^{i}\right) \in D^{i}(p, q)$ for each consumer $i$, and therefore, 
using the lemma above, in period $\hat{t}$, state $\hat{s}$, for every consumer $i, p_{\hat{t}}(\hat{s}) x_{\hat{t}}^{i}(\hat{s})+q_{\hat{t}}(\hat{s}) z_{\hat{t}}^{i}(\hat{s}) \geq$ $W^{i}\left(p, q, z^{i}\right)_{\hat{t}}(\hat{s})$, and for some consumer $i, p_{\hat{t}}(\hat{s}) x_{\hat{t}}^{i}(\hat{s})+q_{\hat{t}}(\hat{s}) z_{\hat{t}}^{i}(\hat{s})>W^{i}\left(p, q, z^{i}\right)_{\hat{t}}(\hat{s})$. Moreover, the definition of equilibrium implies $\sum_{i=1}^{I} q_{\hat{t}}(\hat{s}) z_{\hat{t}}^{i}(\hat{s})=0$, and $\sum_{i=1}^{I}\left[p_{\hat{t}}(\hat{s}) A_{\hat{t}}(\hat{s})+q_{\hat{t}}(\hat{s})\right] z_{\hat{t}-1}^{i}(\hat{s})=$ 0 , and therefore,

$$
\begin{aligned}
\sum_{i=1}^{I} p_{\hat{t}}(\hat{s}) w_{\hat{t}}^{i}(\hat{s}) & =\sum_{i=1}^{I} p_{\hat{t}}(\hat{s}) \dot{x}_{\hat{t}}^{i}(\hat{s})+\sum_{i=1}^{I} q_{\hat{t}}(\hat{s}) z_{\hat{t}}^{i}(\hat{s}) \\
& >\sum_{i=1}^{I} W^{i}\left(p, q, z^{i}\right)_{\hat{t}}(\hat{s}) \\
& =\sum_{i=1}^{I}\left[p_{\hat{t}}(\hat{s}) A_{\hat{t}}(\hat{s})+q_{\hat{t}}(\hat{s})\right] z_{\hat{t}-1}^{i}(\hat{s})+\sum_{i=1}^{I} p_{\hat{t}}(\hat{s}) w_{\hat{t}}^{i}(\hat{s}) \\
& =\sum_{i=1}^{I} p_{\hat{t}}(\hat{s}) w_{\hat{t}}^{i}(\hat{s}),
\end{aligned}
$$

a contradiction.

Using the notation presented here, the result in Geanakoplos and Polemarchakis (1986) can be approximately formulated as follows. Consider a two-period Radner-GEI economy with finitely many states of the world, assets, and consumers. Suppose in period 1, there is no consumption or endowment, and only asset trade is possible, and in period 2, in each state, assets payoff in a numéraire commodity. For a given portfolio allocation, $\left(\left(z^{i}\right)_{i=1}^{I}\right.$ satisfying $\left.\sum_{i}=\dot{z}^{i}=0,\right)$ and a commodity price system $\not \dot{p}$, the restricted budget set for consumer $i$ is

$$
\dot{B}^{i}\left(\dot{p}, \dot{z}^{i}\right)=\left\{x^{i} \mid \text { for every } s, \dot{p}_{2}(s) x_{2}^{i}(s) \leq \dot{p}_{2}(s) w_{2}^{i}(s)+\dot{p}_{2}(s) A_{2}(s) \dot{z}^{i}\right\}
$$

and the restricted demand $\operatorname{set}^{16}$ for consumer $i$ is

$$
\dot{D}^{i}\left(\not{p}, \dot{z}^{i}\right)=\left\{x^{i} \in \dot{B}^{i}\left(\not{p}, \dot{z}^{i}\right) \mid \dot{x}^{i} \in \dot{B}^{i}\left(\not{p}, \dot{z}^{i}\right) \Rightarrow x^{i} \succeq^{i} \dot{x}^{i}\right\}
$$

For a given portfolio allocation, $\left(\left(z^{i}\right)_{i=1}^{I}\right.$ satisfying $\left.\sum_{i}=\dot{z}^{i}=0,\right)$ a spot-market equilibrium is a collection $\left(\not p,\left(\dot{x}^{i}\right)_{i=1}^{I}\right)$, where $\not \dot{p}$ is a commodity price system, for every $i, x^{i} \in \dot{B}^{i}\left(p^{\prime}, z^{i}\right)$,

\footnotetext{
${ }^{16}$ As mentioned in Geanakoplos and Polemarchakis (1986), restricted demand includes optimization over consumption plans, but not over portfolio plans.
} 
and for every $s, \sum_{i} x_{2}^{i}(s)=\sum_{i} w_{2}^{i}(s)$. Geanakoplos and Polemarchakis (1986) show, approximately, that for generic such two-period Radner-GEI economies, if $\left(p, q ;\left(x^{i}, z^{i}\right)_{i=1}^{I}\right)$ is a Radner equilibrium, then there exists a portfolio re-distribution $\left(\dot{z}^{i}\right)_{i=1}^{I}$ satisfying $\sum_{i} z^{i}=0$, and a commodity price system $\dot{p}$ such that $\left(\dot{p},\left(\dot{x}^{i}\right)_{i=1}^{I}\right)$ is a spot-market equilibrium, and $\left(\hat{x}^{i}\right)_{i=1}^{I}$ Pareto dominates $\left(x^{i}\right)_{i=1}^{I} \cdot{ }^{17}$ As documented in the corollary below, (its proof is a re-application of the theorem above,) re-distributions of portfolio holdings cannot induce spot-market price changes that lead to Allais-Malinvaud improvements.

Corollary 1. Let $\left(p, q ;\left(x^{i}, z^{i}\right)_{i=1}^{I}\right)$ be a Radner equilibrium. For every portfolio re-distribution $\left(\dot{z}^{i}\right)_{i=1}^{I}$ satisfying $\sum_{i} \dot{z}^{i}=0$, and a corresponding spot-market equilibrium $\left(\dot{p},\left(\dot{x}^{i}\right)_{i=1}^{I}\right)$, the commodity allocation $\left(\hat{x}^{i}\right)_{i=1}^{I}$ does not Allais-Malinvaud dominate $\left(x^{i}\right)_{i=1}^{I}$.

\section{Incomplete Markets, Sequential Trade, and Bankruptcy-Limited Liability}

With trade over time, and with promises of future delivery based on present information, it can be that a consumer's present promise to repay is more than she can actually deliver in some states of the world in the future. In such states, a consumer is bankrupt, in the sense that her assets are less than her liabilities. ${ }^{18}$ In an economy with limited liability

\footnotetext{
${ }^{17}$ As mentioned in their paper, their result is slightly more general, in that it holds when asset holdings are further required to be affordable at the Radner equilibrium asset prices. The notation presented here is chosen to provide a close correspondence to their definition of constrained efficiency. It is easy to see that incorporating this generalization, the implication in the corollary below is still true.

${ }^{18}$ In a Radner-GEI economy, default is ruled out exogenously by requiring a consumer to trade in those consumption and portfolio plans for which she is able to fulfill her promises of delivery in every period, and
} 
and market-mediated trade, there can be chain reactions of default and bankruptcy, because agents can be buyers of some assets and sellers of others, and default by some debtors leads to partial recovery for their creditors, and this might force these creditors to default on their debt to others. In such an economy, a natural notion of equilibrium, and economic conditions under which an equilibrium exists are presented in the early and seminal work by Dubey, Geanakoplos, and Shubik (2003), (based on work going back to 1988,) and in papers by Zame (1993), by Geanakoplos and Zame (1997), by Modica, Rustichini, and Tallon (1999), by Araujo and Pascoa (2002), and by Sabarwal (2003).

When liability of a consumer is limited, do prices allocate commodities efficiently in markets they serve? This question is investigated here in an extension of the Radner-GEI model in which a consumer's liability is limited by exemptions in bankruptcy law, as presented in Sabarwal (2003). ${ }^{19}$ Allais-Malinvaud efficiency is applicable here, but the price system bears an additional burden, because repayments on assets are determined endogenously. In other words, in addition to reflecting scarcity, prices also affect the financial situation of a consumer, and this feeds back into default rates on assets, and that in turn affects prices of commodities and assets. It is shown that every bankruptcy equilibrium is Allais-Malinvaud efficient. Therefore, in economies with limited liability and endogenous bankruptcy, a comin every state of the world.

${ }^{19}$ The model in Sabarwal (2003) is a multi-period model of bankruptcy, it permits a role for credit limits and default history in equilibrium, and it remains very close in spirit to Radner-GEI economies. Related (two-period) models are presented in Dubey, Geanakoplos, and Shubik (2003), in Geanakoplos and Zame (1997), in Modica, Rustichini, and Tallon (1999), and in Araujo and Pascoa (2002). Multi-period models of default with complete markets are presented in Kehoe and Levine (1993), and in Alvarez and Jermann (2000), and a model with incomplete markets is presented in Zame (1993). 
petitive price system continues to allocate commodities efficiently in markets it serves.

The model of economic activity in Sabarwal (2003) can be motivated briefly as follows. As in a Radner-GEI economy, there are consumption goods and assets, and consumers use assets to move income among different time periods and among different states of the world to finance a consumption plan that they desire most. However, consumers might be able to sell promises of future delivery that they might not be able to fulfill in every state of the world. Consumers can sell assets subject to an exogenously specified credit limit system that can otherwise depend fairly generally on default history. At the time of repayment, creditors have some claim to a debtor's income, but bankruptcy law provides some exemptions to this claim. ${ }^{20}$ A debtor's income up to the value of these exemptions is exempted from forfeiture, even if she has debt outstanding. Although creditors cannot reach into a debtor's exemptions to recover their money, they have a prior claim to the excess of a debtor's income over the value of her exemptions. If a consumer's income minus her exemptions is sufficient to repay her creditors, she is required by law to pay her debts fully. From such a consumer, there is no loss on any asset, and her disposable income is what remains of her income after paying off what she owes. If a consumer's income minus her exemptions is insufficient to repay her creditors, she is bankrupt. From every bankrupt consumer, a Court confiscates the excess of her income over her exemptions, determines the loss from her on each asset based on the method of proportional recovery, and discharges her debts. The disposable income of each bankrupt consumer is the value of her exemptions. ${ }^{21}$ Consumers use their disposable

\footnotetext{
${ }^{20}$ Examples of exemptions are (some of the) value of homes, vehicles, retirement accounts, furniture, clothes, and other personal property. A debtor cannot in reality contract away her exemptions, because such a contract is not legally enforceable.

${ }^{21}$ This model abstracts some essential components of bankruptcy under Chapter 7 of the United States
} 
income to finance their consumption. Total loss on an asset is the aggregate of loss from each consumer on this asset. The ratio of total loss on an asset to total debt owed on it is the default rate on the asset. Creditors bear the loss in proportion to their asset holdings.

In this view, assets are standardized contracts, and a bank or a credit institution serves mainly as a check-point that imposes a credit limit constraint on a consumer, if she wants to sell a promise for future delivery of some commodity. As long as a consumer's promise for future delivery satisfies the constraint imposed by this check-point, she may sell such promises. Trade is mediated through asset-backed securities, where loans are aggregated to manufacture a composite security, pieces of which are traded in asset markets. A consumer purchasing a unit of this asset gets a slice of the underlying loans, and bears the average default risk on them. A natural notion of equilibrium in such an economy is a collection of prices, default rates, and individual consumption and portfolio plans, such that consumers are optimizing, markets are clearing, and the default rate on an asset equals the ratio of total loss on that asset to total debt owed on it.

The model is formalized as follows. The basic concepts of time, uncertainty, commodities, consumption plans, assets, portfolio plans, and prices of commodities and assets remain the same as in the Radner-GEI model. To determine the financial position of a consumer, it is useful to notationally distinguish assets, or receipts of income, from liabilities, or promises of delivery. A convenient notation for that is based on the usual notation for distinguishing the positive and negative parts of a vector, as follows: for any $\xi \in \Re^{K}, \xi_{+}$denotes the positive part of $\xi$, and it is the vector with $k$-th component $\xi_{k}$, if $\xi_{k} \geq 0$, and 0 otherwise, and $\xi_{-}$ Bankruptcy Code. Chapter 7 bankruptcies account for a large majority (about 70 percent) of all personal bankruptcies, and personal bankruptcies account for about 95 percent of all bankruptcies. 
denotes the negative part of $\xi$, and it is the vector with $k$-th component $-\xi_{k}$, if $\xi_{k} \leq 0$, and 0 otherwise. Thus, for any $\xi \in \Re^{K}, \xi_{+} \geq 0, \xi_{-} \geq 0$, and $\xi=\xi_{+}-\xi_{-}$.

Accounting for the financial effects of the legal process for bankruptcy results in nonconvexities in the budget set of a consumer, and therefore, this model has a continuum of consumers $I=[0,1]$, indexed $i \in I$, with $(I, \mathcal{B}, \mu)$ a measure space, and $\mu$ a complete, finite, atomless measure. Each consumer $i$ has a preference relation, $\succeq^{i} \subset X \times X$, which is complete, reflexive, transitive, convex, continuous, and strongly monotone, $\left(x>x \Rightarrow x \succ^{i} \dot{x},\right)^{22}$ and an endowment, $w^{i}=\left(w_{t}^{i}\right)_{t=1}^{T} \in X$. It is assumed that the collection of endowments, $\left(w^{i}\right)_{i \in I}$, lies in a bounded set, it satisfies $\inf _{i} w^{i} \gg 0$, and the map $i \mapsto\left(\succeq^{i}, w^{i}\right)$ is measurable. When convenient, $x_{t}^{i}(s)$ denotes a consumption plan for consumer $i$ in period $t$, state $s$, and $\left(x_{t}^{i}(s)\right)_{i \in I}$ denotes a consumption profile in period $t$, state $s$.

A default rate on an asset is a number between 0 and 1 that signifies the proportion of debt that is not recoverable on this asset. The default rate space in period $t=1$ is $\nabla_{1}=$ $\{0\} \subset \mathcal{R}_{1}$, and in period $t \geq 2$ is $\nabla_{t}=\left\{\alpha_{t} \in \mathcal{R}_{t}^{J} \mid 0 \leq \alpha_{t} \leq 1\right\}$, where 0 is the vector of zeros, and 1 the vector of ones, both in $\mathcal{R}_{t}^{J}$. The default rate space is $\nabla=\underset{t=1}{\stackrel{T}{\times}} \nabla_{t}$. A default rate system is an element $\alpha \in \nabla$, with $\alpha_{t}(s)_{j}$ the default rate on asset $j$ in period $t$, state $s$.

Abstracting some components from the legal framework of bankruptcy law, it is assumed that (1) there is an exemption - that is, a bundle of goods such that for each good, the value of a consumer's endowment of this good up to the value of this good in the exemption bundle is exempted from forfeiture even if she has debts outstanding, (2) a creditor has a prior claim to the excess of a debtor's income over the value of the debtor's exemption, and (3) the claim of any creditor on a consumer's income has the same priority as the claim of

\footnotetext{
${ }^{22}$ The notions of indifference $\left(\sim^{i}\right)$ and strict preference $\left(\succ^{i}\right)$ are the usual ones.
} 
any other creditor. These assumptions describe the rights of creditors and debtors in the model. The first assumption implies that the exemption value of a consumer is the sum over commodities of the minimum of value of her endowment of each commodity, and the value of this commodity in the exemption bundle. The second assumption implies that if the liquidation value of a consumer - that is, the excess of her (gross) income over her exemption value - is greater than the debt she owes, her liability is the debt she owes. Otherwise, her liability is her liquidation value. The third assumption implies that creditors share losses from a debtor in proportion to what she owes them. If we think of unsecured lending as lending that is not secured by an already identified portion of future income, but only by a general claim on it, then this model has only unsecured lending. ${ }^{23}$ To ensure that in each period and state, the value of the exemption is not zero, it is assumed that an exemption is an element $e \in X$, such that $e \gg 0$.

The financial position of an consumer can be formalized as follows. Suppose $(p, q, \alpha)$ is a price and default rate system, and $z^{i}$ is a portfolio plan for consumer $i$. In period $t$, state $s$, consumer $i$ 's endowment income is $p_{t}(s) w_{t}^{i}(s)$, she is supposed to receive $\left[p_{t}(s) A_{t}(s)+\right.$ $\left.q_{t}(s)\right] z_{t-1}^{i}(s)_{+}$from her period $t-1$ asset purchases, but expects to receive only $\sum_{j=1}^{J}(1-$ $\left.\alpha_{t}(s)_{j}\right)\left[p_{t}(s) A_{t}(s)_{j}+q_{t}(s)_{j}\right]\left(z_{t-1}^{i}(s)_{+}\right)_{j}$, and she owes $\left[p_{t}(s) A_{t}(s)+q_{t}(s)\right] z_{t-1}^{i}(s)_{-}$. The gross income of consumer $i$ in period $t$, state $s$ is the sum of her endowment income, and what she expects to receive in that period and state. Her exemption value in that period and state is $\epsilon^{i}\left(p, q, \alpha, z^{i}\right)_{t}(s)=\sum_{\ell=1}^{L} \min \left(p_{t}(s)_{\ell} w_{t}^{i}(s)_{\ell}, p_{t}(s)_{\ell} e_{t}(s)_{\ell}\right)$, and her liquidation value in that period and state is the excess of her gross income over her exemption value. Consumer

\footnotetext{
${ }^{23} \mathrm{An}$ asset in this model can, but need not, be interpreted as a reduced form representation of the unsecured portion of an underlying asset.
} 
$i$ is bankrupt in period $t$, state $s$, if in that period and state, her liquidation value is less than what she owes. Her liability in period $t$, state $s$ is the lesser of her liquidation value in that period and state, and what she owes in it. An implication of these definitions is that if we think of default as a situation in which a consumer repays less than what she owes, then in this model, a consumer defaults exactly when she is bankrupt. ${ }^{24}$ The net income of consumer $i$ in period $t$, state $s$ is

$$
\begin{aligned}
f^{i}\left(p, q, \alpha, z^{i}\right)_{t}(s)= & p_{t}(s) w_{t}^{i}(s)+\sum_{j}\left(1-\alpha_{t}(s)_{j}\right)\left[p_{t}(s) A_{t}(s)_{j}+q_{t}(s)_{j}\right]\left(z_{t-1}^{i}(s)_{+}\right)_{j} \\
& -\left[p_{t}(s) A_{t}(s)+q_{t}(s)\right] z_{t-1}^{i}(s)_{-} .
\end{aligned}
$$

For $t=1$, this reduces to $p_{1}(s) w_{1}^{i}(s)$. The disposable income of consumer $i$ in period $t$, state $s$ is

$$
W^{i}\left(p, q, \alpha, z^{i}\right)_{t}(s)=\max \left(f^{i}\left(p, q, \alpha, z^{i}\right)_{t}(s), \epsilon^{i}\left(p, q, \alpha, z^{i}\right)_{t}(s)\right)
$$

For $t=1$ this reduces to $p_{1}(s) w_{1}^{i}(s)$. It is trivial to check that consumer $i$ is bankrupt in period $t$, state $s$, if and only if $f^{i}\left(p, q, \alpha, z^{i}\right)_{t}(s)<\epsilon^{i}\left(p, q, \alpha, z^{i}\right)_{t}(s)$. In this case, her disposable income is $\epsilon^{i}\left(p, q, \alpha, z^{i}\right)_{t}(s)$, and she contributes $(\epsilon-f)^{i}\left(p, q, \alpha, z^{i}\right)_{t}(s)=\epsilon^{i}\left(p, q, \alpha, z^{i}\right)_{t}(s)-$ $f^{i}\left(p, q, \alpha, z^{i}\right)_{t}(s)$ to the pool of bad debts. Otherwise, she contributes nothing to the pool of bad debts. The loss from consumer $i$ in period $t$, state $s$ is $\lambda^{i}\left(p, q, \alpha, z^{i}\right)_{t}(s)=\max ((\epsilon-$ $\left.f)^{i}\left(p, q, \alpha, z^{i}\right)_{t}(s), 0\right)$. The debt owed by consumer $i$ on asset $j$ in period $t$, state $s$ is

\footnotetext{
${ }^{24}$ This does not mean that she has no choice about whether to default or not. She still controls her portfolio choice, which affects her bankruptcy status, and hence her default status. In this model, a consumer can only prevent the value of her exemptions from being confiscated. There is no default over and above this value, because a creditor has a prior right to contractual delivery of the (value of) promised commodities, and a Court upholds this right, subject to bankruptcy law; therefore, there is no sense in which a debtor can default on some part of her commitment that is less than her full commitment, but more than what she can shield under bankruptcy law.
} 
$\gamma^{i}\left(p, q, \alpha, z^{i}\right)_{t}(s)_{j}=\left[p_{t}(s) A_{t}(s)_{j}+q_{t}(s)_{j}\right]\left(z_{t-1}^{i}(s)_{-}\right)_{j}$. The ratio of loss from consumer $i$ in a period and state to what she owes in it is the proportion of her debt that creditors cannot recover. Therefore, the loss from consumer $i$ on asset $j$ is this proportion of what she owes on asset $j$. Formally, the loss from consumer $i$ on asset $j$ in period $t$, state $s$ is

$$
\begin{aligned}
& \beta^{i}\left(p, q, \alpha, z^{i}\right)_{t}(s)_{j}= \\
& = \begin{cases}\frac{\lambda^{i}\left(p, q, \alpha, z^{i}\right)_{t}(s)}{\left[p_{t}(s) A_{t}(s)+q_{t}(s)\right] z_{t-1}^{i}(s)} \gamma_{-}^{i}\left(p, q, \alpha, z^{i}\right)_{t}(s)_{j} & \text { if }\left[p_{t}(s) A_{t}(s)+q_{t}(s)\right] z_{t-1}^{i}(s)_{-}>0, \text { and } \\
0 & \text { otherwise. }\end{cases}
\end{aligned}
$$

Notice that for $t=1, \beta^{i}\left(p, q, \alpha, z^{i}\right)_{1}(s)_{j}=\gamma^{i}\left(p, q, \alpha, z^{i}\right)_{1}(s)_{j}=0$. This summarizes the financial position of a consumer in the model.

Credit limits and trading restrictions are formalized as follows. ${ }^{25}$ Let $Q$ be defined as follows, $Q=\left\{q \in \mathcal{R}_{+}^{J} \mid\right.$ there is $p \in \mathcal{R}_{+}^{L}$ and $\left.(p, q) \in \Delta\right\}$, and for every $j, s, t$ with $t \leq T-1$, let $Q_{t}(s)_{j}=\left\{q \in Q \mid q_{t}(s)_{j} \geq \frac{1}{2 J}\right\}$. A credit limit for consumer $i$ is a continuous function $C^{i}: Q \times \mathcal{R}_{+}^{J} \rightarrow \mathcal{R}_{+}^{J}$ (mapping $(q, \beta)$ to $\left.C^{i}(q, \beta)\right)$ that is weakly decreasing in $\beta{ }^{26}$ To reflect dependence of a credit limit on information available in a particular period, it is assumed that for every $t, C^{i}(q, \beta)_{t}$ depends only on $q_{t}$ and $\beta_{t}$, where $t \leq t$. A credit limit system is a map $C: i \mapsto C^{i}$. It is assumed that this map is measurable, ${ }^{27}$ that $C^{i}$ evaluated at $\beta=0$ when viewed as a function of $i$ and $q$ is bounded, and that for every $j, s, t$ with $t \leq T-1, \mu\left(\left\{i \in I \mid \inf _{q \in Q_{t}(s)_{j}, \beta \in \mathcal{R}_{+}^{J}} C^{i}(q, \beta)_{t}(s)_{j}>0\right\}\right)>0$, and if $q_{t}(s)_{j}=0$, then $\mu\left(\left\{i \in I \mid C^{i}(q, 0)_{t}(s)_{j}=0\right\}\right)=\mu(I)$. Trading restrictions are formalized as follows. Let $(p, q, \alpha)$ be a price and default rate system and $C^{i}$ a credit limit for consumer $i$. A

\footnotetext{
${ }^{25}$ For more details, see Sabarwal (2003)

$\left.{ }^{26} \beta \leq \dot{\beta} \Rightarrow C^{i}(\cdot, \dot{\beta}) \leq C^{i}(\cdot, \beta)\right)$. by the topology of closed convergence.
}

${ }^{27}$ The target space is the space of closed subsets of $Q \times \mathcal{R}_{+}^{J} \times \mathcal{R}_{+}^{J}$, along with the sigma-algebra generated 
portfolio plan $z^{i}$ is $\left(C^{i}, p, q, \alpha\right)$ - admissible if for every $j, s, t$ with $t \leq T-1$, if there is $s^{\prime} \in E_{t}(s)$ with $A_{t+1}\left(s^{\prime}\right)_{j}>0$, , then $A_{t+1}(s)_{j}\left(z_{t}^{i}(s)_{-}\right)_{j} \leq C^{i}\left(q, \beta^{i}\left(p, q, \alpha, z^{i}\right)\right)_{t}(s)_{j}$, otherwise $\left(z_{t}^{i}(s)_{-}\right)_{j} \leq C^{i}\left(q, \beta^{i}\left(p, q, \alpha, z^{i}\right)\right)_{t}(s)_{j}$. In this definition, $E_{t}(s)$ is the event in $\mathcal{S}_{t}$ that contains $s$, and $\beta^{i}\left(p, q, \alpha, z^{i}\right)$ is the profile of loss from consumer $i$ on every asset in every period and state. The concept of admissibility formalizes the idea that an consumer's ability to take on debt depends, among other things, on an consumer-specific component that includes her default history and on the price of the asset, which reflects the riskiness of the asset. $^{28}$

A consumer's budget set consists of all consumption and (admissible) portfolio plans that are affordable, and her demand set consists of those plans in the budget set that are optimal with respect to her preference relation. Formally, let $C$ be a credit limit system, and $(p, q, \alpha)$ a price and default rate system. For consumer $i$, a consumption and portfolio plan $\left(x^{i}, z^{i}\right)$ is $(p, q, \alpha)$-affordable, if in every period $t$ and state $s, p_{t}(s) x_{t}^{i}(s)+q_{t}(s) z_{t}^{i}(s) \leq$ $W^{i}\left(p, q, \alpha, z^{i}\right)_{t}(s)$. The budget set for consumer $i$ is

$$
B^{i}(p, q, \alpha)=\left\{\begin{array}{l|l}
\left(x^{i}, z^{i}\right) \in X \times Z & \begin{array}{l}
\left(x^{i}, z^{i}\right) \text { is }(p, q, \alpha) \text {-affordable, and } \\
z^{i} \text { is }\left(C^{i}, p, q, \alpha\right) \text {-admissible }
\end{array}
\end{array}\right\},
$$

and the demand set for consumer $i$ is

$$
D^{i}(p, q, \alpha)=\left\{\left(x^{i}, z^{i}\right) \in B^{i}(p, q, \alpha) \mid\left(\dot{x}^{i}, \dot{z}^{i}\right) \in B^{i}(p, q, \alpha) \Rightarrow x^{i} \succeq^{i} \dot{x}^{i}\right\}
$$

A Radner-GEI economy with bankruptcy-limited liability is a collection

$$
\left\{\mathcal{S}, A,\left(\succeq^{i}, w^{i}\right)_{i \in I}, e, C\right\},
$$

\footnotetext{
${ }^{28}$ Using portfolio admissibility, a bound on asset sales follows immediately.
} 
where $\mathcal{S}=\left(\mathcal{S}_{t}\right)_{t=1}^{T}$ is an information structure, $A=\left(A_{t}\right)_{t=1}^{T}$ is an asset structure, $\left(\succeq^{i}, w^{i}\right)$ is the preference relation and endowment of consumer $i, e$ is an exemption, and $C$ is a credit limit system. A bankruptcy equilibrium is a collection $\left(p, q, \alpha ;\left(x^{i}, z^{i}\right)_{i \in I}\right)$, where $(p, q, \alpha)$ is a price and default rate system, and

- for almost every $i \in I, \quad\left(x^{i}, z^{i}\right) \in D^{i}(p, q, \alpha)$,

- for every $s, t, \quad \int_{I} x_{t}^{i}(s) d i=\int_{I} w_{t}^{i}(s) d i, \quad$ and $\quad \int_{I} z_{t}^{i}(s) d i=0$,

- for every $j, s$, and every $t \geq 2$,

$$
\alpha_{t}(s)_{j} \in \begin{cases}\left\{\frac{\int_{I} \beta^{i}\left(p, q, \alpha, z^{i}\right)_{t}(s)_{j} d i}{\int_{I} \gamma^{i}\left(p, q, \alpha, z^{i}\right)_{t}(s)_{j} d i}\right\} & \text { if } \int_{I} \gamma^{i}\left(p, q, \alpha, z^{i}\right)_{t}(s)_{j} d i>0, \text { and } \\ {[0,1]} & \text { if } \int_{I} \gamma^{i}\left(p, q, \alpha, z^{i}\right)_{t}(s)_{j} d i=0 .\end{cases}
$$

The first condition requires equilibrium consumption and portfolio plans to be optimal for almost every consumer. The second condition requires markets for commodities and assets to clear. The third condition requires the equilibrium default rate on an asset to equal the ratio of total loss on that asset to total debt owed on it, if total debt owed on it is not zero. If total debt owed on an asset is zero, the default rate can be any number between zero and one. $^{29}$

From a consumer's preference relation, and for a given consumption plan, a natural preference for consumption in a particular period and state can be derived as above. The concept of an Allais-Malinvaud efficient allocation needs an obvious modification as follows. A profile of consumption plans in period $t$, state $s,\left(x_{t}^{i}(s)\right)_{i \in I}$, is an allocation in period $t$,

\footnotetext{
${ }^{29}$ If total debt owed on asset $j$ in any period $t$, state $s$ is zero, and the market for asset $j$ clears, then it is clear that the value of $\alpha_{t}(s)_{j}$ is irrelevant. The question of existence of equilibrium is considered in Sabarwal
} (2003). 
state $s$, if $\int_{I} x_{t}^{i}(s) d i=\int_{I} w_{t}^{i}(s) d i$. A profile of consumption plans, $\left(x^{i}\right)_{i \in I}$, is an allocation, if for every period $t$, state $s,\left(x_{t}^{i}(s)\right)_{i \in I}$ is an allocation in period $t$, state $s$. Let $\left(x^{i}\right)_{i \in I}$ be an allocation. A period $\hat{t}$, state $\hat{s}$ allocation $\left(\hat{x}_{\hat{t}}^{i}(\hat{s})\right)_{i \in I}$ Allais-Malinvaud dominates allocation $\left(x^{i}\right)_{i \in I}$ in period $\hat{t}$, state $\hat{s}$, if for almost every consumer $i, x_{\hat{t}}^{i}(\hat{s}) \succeq_{\hat{t}}^{i}(\hat{s}) x_{\hat{t}}^{i}(\hat{s})$, and for some set $F \subset I$ of consumers with positive measure, for each consumer $i \in F, x_{\hat{t}}^{i}(\hat{s}) \succ_{\hat{t}}^{i}(\hat{s}) x_{\hat{t}}^{i}(\hat{s})$. An allocation $\left(\dot{x}^{i}\right)_{i \in I}$ Allais-Malinvaud dominates allocation $\left(x^{i}\right)_{i \in I}$, if there is some period $\hat{t}$, state $\hat{s}$, such that $\left(\hat{x}_{\hat{t}}^{i}(\hat{s})\right)_{i \in I}$ Allais-Malinvaud dominates $\left(x^{i}\right)_{i \in I}$ in period $\hat{t}$, state $\hat{s}$. An allocation $\left(x^{i}\right)_{i \in I}$ is Allais-Malinvaud efficient, if there is no allocation $\left(x^{i}\right)_{i \in I}$ that Allais-Malinvaud dominates $\left(x^{i}\right)_{i \in I}$. A bankruptcy equilibrium $\left(p, q, \alpha ;\left(x^{i}, z^{i}\right)_{i \in I}\right)$ is AllaisMalinvaud efficient if $\left(x^{i}\right)_{i \in I}$ is Allais-Malinvaud efficient. With these definitions, every bankruptcy equilibrium is Allais-Malinvaud efficient, as the following theorem shows.

Lemma 2. Let $(p, q, \alpha)$ be a price and default rate system, $\left(x^{i}, z^{i}\right) \in D^{i}(p, q, \alpha)$, and $x^{i}$ be another consumption plan for $i$. In period $\hat{t}$, state $\hat{s}$,

$$
\begin{aligned}
& \text { if } \dot{x}_{\hat{t}}^{i}(\hat{s}) \succeq_{\hat{t}}^{i}(\hat{s}) x_{\hat{t}}^{i}(\hat{s}), \text { then } p_{\hat{t}}(\hat{s}) x_{\hat{t}}^{i}(\hat{s})+q_{\hat{t}}(\hat{s}) z_{\hat{t}}^{i}(\hat{s}) \geq W^{i}\left(p, q, \alpha, z^{i}\right)_{\hat{t}}(\hat{s}), \quad \text { and } \\
& \text { if } x_{\hat{t}}^{i}(\hat{s}) \succ_{\hat{t}}^{i}(\hat{s}) x_{\hat{t}}^{i}(\hat{s}), \text { then } p_{\hat{t}}(\hat{s}) x_{\hat{t}}^{i}(\hat{s})+q_{\hat{t}}(\hat{s}) z_{\hat{t}}^{i}(\hat{s})>W^{i}\left(p, q, \alpha, z^{i}\right)_{\hat{t}}(\hat{s}) .
\end{aligned}
$$

This lemma can be proved by replacing $W^{i}\left(p, q, z^{i}\right)_{\hat{t}}(\hat{s})$ with $W^{i}\left(p, q, \alpha, z^{i}\right)_{\hat{t}}(\hat{s})$, and $B^{i}(p, q)$ with $B^{i}(p, q, \alpha)$ in the proof of the previous lemma.

Theorem 2. Every Bankruptcy equilibrium is Allais-Malinvaud efficient.

Proof. Suppose $\left(p, q, \alpha ;\left(x^{i}, z^{i}\right)_{i \in I}\right)$ is a bankruptcy equilibrium, and suppose there is an allocation $\dot{x}$ that Allais-Malinvaud dominates $x=\left(x^{i}\right)_{i \in I}$. It follows that there is period $\hat{t}$, state $\hat{s}$, such that for almost every consumer $i, x_{\hat{t}}^{i}(\hat{s}) \succeq_{\hat{t}}^{i}(\hat{s}) x_{\hat{t}}^{i}(\hat{s})$, and for some set $F \subset I$ of consumers with positive measure, for each consumer $i \in F, x_{\hat{t}}^{i}(\hat{s}) \succ_{\hat{t}}^{i}(\hat{s}) x_{\hat{t}}^{i}(\hat{s})$. Using the 
lemma above, for almost every consumer $i, p_{\hat{t}}(\hat{s}) \dot{x}_{\hat{t}}^{i}(\hat{s})+q_{\hat{t}}(\hat{s}) z_{\hat{t}}^{i}(\hat{s}) \geq W^{i}\left(p, q, \alpha, z^{i}\right)_{\hat{t}}(\hat{s})$, and for each consumer $i \in F, p_{\hat{t}}(\hat{s}) \dot{x}_{\hat{t}}^{i}(\hat{s})+q_{\hat{t}}(\hat{s}) z_{\hat{t}}^{i}(\hat{s})>W^{i}\left(p, q, \alpha, z^{i}\right)_{\hat{t}}(\hat{s})$. It follows that

$$
\begin{aligned}
\int_{I} p_{\hat{t}}(\hat{s}) w_{\hat{t}}^{i}(\hat{s}) d i= & \int_{I} p_{\hat{t}}(\hat{s}) \dot{x}_{\hat{t}}^{i}(\hat{s}) d i+\int_{I} q_{\hat{t}}(\hat{s}) z_{\hat{t}}^{i}(\hat{s}) d i \\
& >\int_{I} W^{i}\left(p, q, \alpha, z^{i}\right)_{\hat{t}}(\hat{s}) d i \\
& =\int_{I} \max \left((\epsilon-f)^{i}\left(p, q, \alpha, z^{i}\right)_{\hat{t}}(\hat{s}), 0\right)+f^{i}\left(p, q, \alpha, z^{i}\right)_{\hat{t}}(\hat{s}) d i \\
& =\int_{I} \lambda^{i}\left(p, q, \alpha, z^{i}\right)_{\hat{t}}(\hat{s}) d i+\int_{I} \sum_{j}\left[p_{\hat{t}}(\hat{s}) A_{\hat{t}}(\hat{s})_{j}+q_{\hat{t}}(\hat{s})_{j}\right] z_{\hat{t}-1}^{i}(\hat{s})_{j} d i \\
& \quad-\int_{I} \sum_{j} \alpha_{\hat{t}}(\hat{s})_{j}\left[p_{\hat{t}}(\hat{s}) A_{\hat{t}}(\hat{s})_{j}+q_{\hat{t}}(\hat{s})_{j}\right]\left(z_{\hat{t}-1}^{i}(\hat{s})_{+}\right)_{j} d i+\int_{I} p_{\hat{t}}(\hat{s}) w_{\hat{t}}^{i}(\hat{s}) d i \\
= & \int_{I} p_{\hat{t}}(\hat{s}) w_{\hat{t}}^{i}(\hat{s}) d i+\int_{I} \lambda^{i}\left(p, q, \alpha, z^{i}\right)_{\hat{t}}(\hat{s}) d i \\
& -\sum_{j} \int_{I} \alpha_{\hat{t}}(\hat{s})_{j}\left[p_{\hat{t}}(\hat{s}) A_{\hat{t}}(\hat{s})_{j}+q_{\hat{t}}(\hat{s})_{j}\right]\left(z_{\hat{t}-1}^{i}(\hat{s})_{+}\right)_{j} d i \\
= & \int_{I} p_{\hat{t}}(\hat{s}) w_{\hat{t}}^{i}(\hat{s}) d i+\int_{I} \lambda^{i}\left(p, q, \alpha, z^{i}\right)_{\hat{t}}(\hat{s}) d i \\
& -\sum_{j} \alpha_{t}(s)_{j} \int_{I} \gamma^{i}\left(p, q, \alpha, z^{i}\right)_{t}(s)_{j} d i \\
= & \int_{I} p_{\hat{t}}(\hat{s}) w_{\hat{t}}^{i}(\hat{s}) d i+\int_{I} \lambda^{i}\left(p, q, \alpha, z^{i}\right)_{\hat{t}}(\hat{s}) d i-\int_{I} \sum_{j} \beta^{i}\left(p, q, \alpha, z^{i}\right)_{t}(s)_{j} d i \\
= & \int_{I} p_{\hat{t}}(\hat{s}) w_{\hat{t}}^{i}(\hat{s}) d i+\int_{I} \lambda^{i}\left(p, q, \alpha, z^{i}\right)_{\hat{t}}(\hat{s}) d i-\int_{I} \lambda^{i}\left(p, q, \alpha, z^{i}\right)_{\hat{t}}(\hat{s}) d i
\end{aligned}
$$

a contradiction.

Notice that this theorem does not imply that a result along the lines of Geanakoplos and Polemarchakis (1986) is not possible for Radner-GEI economies with limited liability. But it does show that a re-distribution of assets in equilibrium, even when accompanied by corresponding spot-market clearing prices, and corresponding equilibrium spot-market default rates cannot induce changes in relative prices that lead to an Allais-Malinvaud improvement. 


\section{References}

Aliprantis, C. D., D. J. Brown, and O. Burkinshaw (1989): "Equilibria in Exchange Economies With a Countable Number of Agents," Journal of Mathematical Analysis and Applications, 142, 250-299.

(1990): Existence and Optimality of Competitive Equilibria. Springer-Verlag.

Allais, M. (1943): "A la recherche d'une discipline économique," Ateliers Industria, Tome I.

(1947): Economie et intéret. Impremerie Nationale, Paris, 1947.

Alvarez, F., and U. Jermann (2000): "Efficiency, Equilibrium, and Asset Pricing with Risk of Default," Econometrica, 68(4), 775-797.

Araujo, A., And M. Pascoa (2002): "Bankruptcy in a Model of Unsecured Claims," Economic Theory, 20(3), 455-481.

Balasko, Y., And K. Shell (1980): "The Overlapping-Generations Model, I: The case of pure exchange without money," Journal of Economic Theory, 23, 281-306.

Diamond, P. A. (1967): "The Role of a Stock Market in a General Equilibrium Model with Technological Uncertainty," American Economic Review, 57(4), 759-776.

Dubey, P., J. Geanakoplos, and M. Shubik (2003): "Default and Punishment in General Equilibrium," Cowles Foundation Discussion Paper No.1304RRR; based on CFDP No. 879 (1988), 879R (1989), 1247 (2000), 1304 (2001), 1304R, 1304RR (2002).

Duffie, D., And W. Shafer (1985): "Equilibrium in Incomplete Markets: I: A Basic Model of Generic Existence," Journal of Mathematical Economics, 14(3), 285-300.

(1986): "Equilibrium in Incomplete Markets: II: Generic Existence in Stochastic Economies," Journal of Mathematical Economics, 15(3), 119-216.

Geanakoplos, J., and H. Polemarchakis (1986): "Existence, Regularity, and Constrained Suboptimality of Competitive Allocations when Markets are Incomplete," in Uncertainty, Information, and Communication: Essays in Honor of Kenneth Arrow, Vol. 3, ed. by W. P. Heller, R. M. Starr, and D. A. Starrett, pp. 65-95. Cambridge University Press.

(1990): "Observation and Optimality," Journal of Mathematical Economics, 19(1), 153-165.

Geanakoplos, J., and W. Zame (1997): "Collateral, Default and Market Crashes," Mimeo.

Grossman, S. J. (1977): "A Characterization of the Optimality of Equilibrium in Incomplete markets," Journal of Economic Theory, 15(1), 1-15. 
Hart, O. (1975): "On the Optimality of Equilibrium when the Market Structure is Incomplete," Journal of Economic Theory, 11(3), 418-443.

Kehoe, T., And D. Levine (1993): "Debt-Constrained Asset Markets," The Review of Economic Studies, 60(4), 865-888.

Malinvaud, E. (1953): "Capital Accumulation and Efficient Allocation of Resources," Econometrica, 21(2), 233-268.

(1961): "The Analogy Between Atemporal and Intertemporal Theories of Resource Allocation," The Review of Economic Studies, 28(3), 143-160.

573.

Modica, M., A. Rustichini, and J.-M. Tallon (1999): "Unawareness and Bankruptcy: A General Equilibrium Model," Economic Theory, 12(2), 259-292.

Newbery, D. M., and J. E. Stiglitz (1982): "The Choice of Technique and the Optimality of Market Equilibrium with Rational Expectations," Journal of Political Economy, $90(2), 223-246$.

Polemarchakis, H. M. (1990): "The Economic Implications of an Incomplete Asset Market," American Economic Review, 80(2), 280-283.

Radner, R. (1972): "Existence of Equilibrium of Plans, Prices, and Price Expectations in a Sequence of Markets," Econometrica, 40(2), 289-303.

SABARwaL, T. (2003): "Competitive Equilibria with Incomplete Markets and Endogenous Bankruptcy," Contributions to Theoretical Economics, 3(1), Art. 1.

Samuelson, P. A. (1958): "An Exact Consumption-Loan Model of Interest With or Without the Social Contrivance of Money," Journal of Political Economy, 66, 467-482.

Shell, K. (1971): "Notes on the Economics of Infinity," Journal of Political Economy, 79, 1002-1011.

Stiglitz, J. E. (1982): "The Inefficiency of Stock Market Equilibrium," The Review of Economic Studies, 49, 241-261.

Zame, W. (1993): "Efficiency and the Role of Default When Security Markets are Incomplete," American Economic Review, 83(5), 1142-1164. 


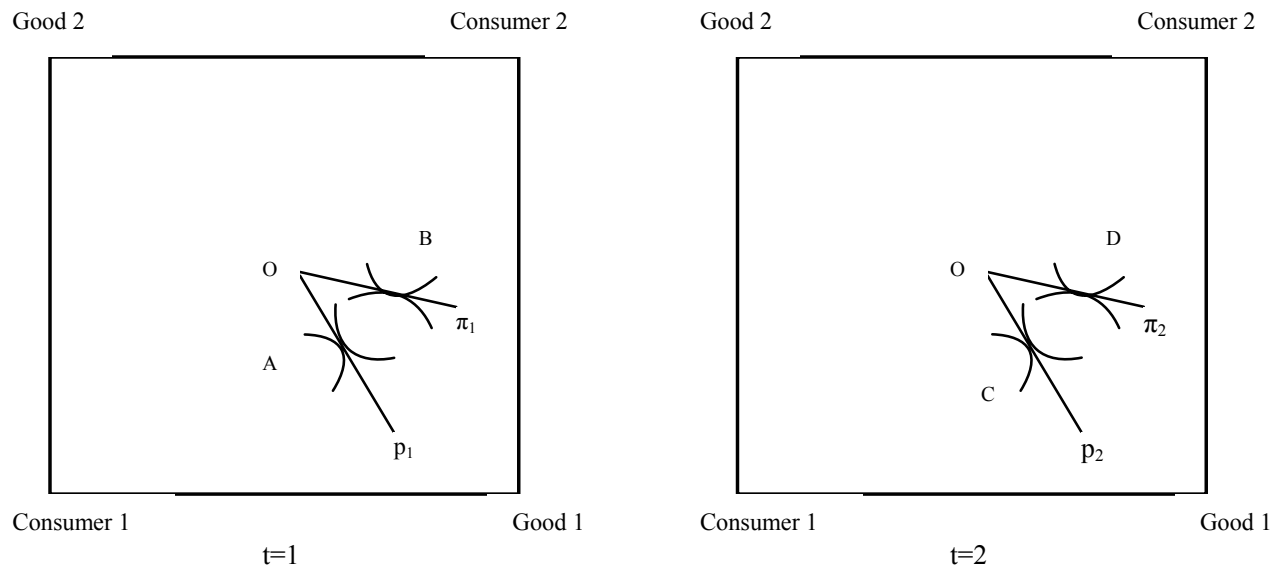

Figure 1: Hart's Example (1975) 